E3S Web of Conferences 1, 03004 (2013)

DOI: $10.1051 / \mathrm{e} 3 \operatorname{sconf} / 20130103004$

(C) Owned by the authors, published by EDP Sciences, 2013

\title{
Anthropogenic Vanadium emissions to air and ambient air concentrations in North-West Europe
}

\author{
A. H. J. Visschedijk ${ }^{1}$, H. A. C. Denier van der Gon ${ }^{2}, \underline{\text { J. H. J Hulskotte }}^{3}$ and U. Quass ${ }^{4}$ \\ ${ }^{1}$ Department of Climate, Air and Sustainability, TNO, 3584 CB Utrecht, The NETHERLANDS, \\ antoon.visschedijk@tno.nl \\ ${ }^{2}$ Department of Climate, Air and Sustainability, TNO, 3584 CB Utrecht, The NETHERLANDS, \\ hugo.deniervandergon@tno.nl \\ ${ }^{3}$ Department of Climate, Air and Sustainability, TNO, 3584 CB Utrecht, The NETHERLANDS, jan.hulskotte@tno.nl \\ ${ }^{4}$ IUTA e. V., Air Quality \& Sustainable Nanotechnology Unit, D-47229 Duisburg, GERMANY, quass@iuta.de
}

\begin{abstract}
An inventory of Vanadium emissions for North-West Europe for the year 2005 was made based on an identification of the major sources. The inventory covers Belgium, Germany, Denmark, France, United Kingdom, Luxembourg, Netherlands and the OSPAR region of the North Sea. Vanadium emission were calculated bottom-up using energy use activity data and collected fuel and sector-specific emissions factors, taking into account various emission control measures. The NW European emissions were dominated by combustion of heavy fuel oil and petroleum cokes. Total emissions for 2005 amounted to 1569 tons/yr. The major sources are sea going ships (39\%), petroleum refineries (35\%) and industry (19\%). Emission is strongly concentrated at the densely populated cities with major sea ports. The location of sources at or near the major port cities was confirmed by observational data, as was the downward trend in emissions due to emission control, fuel switches in industry and fuel quality improvement. The results show the positive impact of lower sulphur fuels on other possible health relevant air pollutants such as particle bound Vanadium. The emission inventory can be expanded to the full European domain and can be used to for air quality modeling and particularly for the tracing of source contributions from certain types of fossil fuels (petroleum coke and residual fuel oil). Moreover, it will allow the monitoring of changes in fuel use over time.
\end{abstract}

Key words: Heavy metals, Vanadium, emission inventory, heavy fuel oil, shipping, petroleum cokes

\section{Introduction}

Vanadium (V) is a bright white ductile metal belonging to group $\mathrm{V}$ of the periodic system of elements. It has an atomic mass of 55 and belongs to the transition metals. Vanadium is mainly used in steel industry for the production of high-strength and low-alloy. Another important application is its use as a heterogeneous catalyst (i.e. for after treatment of vehicle exhaust gasses). Vanadium is known to be present in both crude oil and coal, in widely varying concentrations. (1-1500 mg/kg). Vanadium in crude oil is concentrated in the heaviest distillation fractions and can reach very high concentrations in derived fuels such as residual oil and petroleum coke. Vanadium emission comes from anthropogenic and natural sources but the anthropogenic contribution dominates especially in densely populated areas such as Western Europe. Vanadium emissions are mainly particle-bound and especially the submicron particle size fraction can travel over long distances making it relevant for trans-boundary air pollution.

Numerous studies have reported acute and chronic respiratory effects due to exposure to vanadium (WHO, 2000). The neurotoxic effects of vanadium and its potential to induce chronic neurological diseases are not well understood but have been associated with depression and Parkinson's disease. Vanadium is an element of concern for Air Quality and exposure of the human population (WHO, 2000).

Information on the origin of Vanadium in ambient aerosol can be obtained from trace element source apportionment studies. For urban as well as rural observation sites, Vanadium appears to be almost exclusively assigned to combustion activities involving heavy petroleum products (e.g., Moreno et al., 2010). The aim of this study was to quantify the most important anthropogenic sources of Vanadium in the Netherlands, Germany, France, the United Kingdom, Belgium, 
Luxembourg, Denmark and the North Sea (OSPAR region) in 2005 .

\section{Methodology to Estimate Vanadium emission}

The combustion of residual petroleum fractions is expected to be the dominating source in NW Europe. The distribution and usage of petroleum cokes (PC) and heavy/residual fuel oil (HFO) was reported by IEA (2011; Fig. 1).

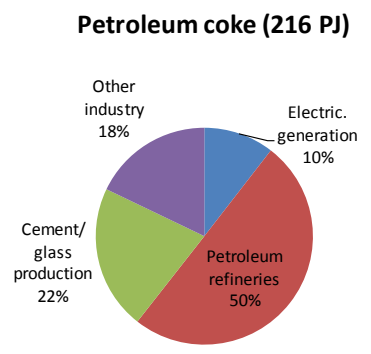

Residual/heavy fuel oil (865 PJ)

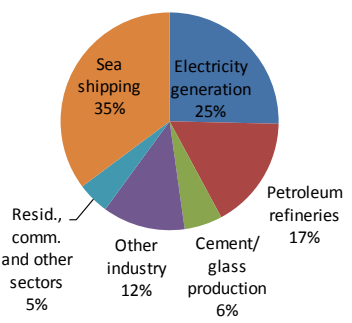

Fig. 1. The use of heavy petroleum products in 2005 in North Western Europe including the OSPAR-North Sea IEA (2011)

Petroleum cokes and HFO are also used as secondary fuels in coal-fired power plants but these facilities are strongly abated with removal efficiencies, although lower than for coal alone, still exceeding 90\% (Meij and Te Winkel, 2005). Oil refineries use $\sim 50 \%$ of all produced petroleum coke. The burning of petroleum coke is mostly the result of Fluid Catalytic Cracking (FCC) catalyst regeneration and the decarbonizing of furnaces, which in an estimated $50 \%$ of the cases took place in 2005 without emission control, like e.g., Electrostatic Precipitator (ESP). Residual oil is used in refinery furnaces without the use of any end-of-pipe pollution control equipment. Both petroleum coke and heavy oil are also used in cement ovens but in this process Vanadium is effectively immobilized in the produced cement and, remaining emission is highly abated by end-of-pipe emission control. Petroleum coke has several other industrial uses such as carbon anode (approx. 10 PJ) and e.g., silicon carbide manufacturing However, these emissions are highly abated. Residual oil is furthermore used in various smaller scale industries and in agriculture as a heating fuel. In these activities no emission control is assumed to take place. The most important use of residual oil is in international shipping. In the OSPAR domain of the North Sea about 300 PJ is used, roughly double the amount used by refineries. Coal use in power plants within the domain was 4618 PJ (IEA, 2011).

Literature data on the Vanadium content of heavy/residual fuel oil show a wide variation. For residual oil a range of $100-10000 \mathrm{mg} / \mathrm{GJ}$ is found in about 20 measurements, with an average value of $2000 \mathrm{mg} / \mathrm{GJ}$ (approx. $100 \mathrm{ppm} \mathrm{V}$ ) with an uncertainty of a factor of 2 .
For petroleum coke, we expect a 2-fold concentration increase in reference to the heavy oil feedstock. For the V content of unintentional coke deposits on FCC catalyst and process equipment an average $\mathrm{V}$ content of 5000 $\mathrm{mg} / \mathrm{GJ}$ ( \pm factor 2) was assumed.

To estimate emission factors an assessment of the Vanadium removal efficiency of control equipment is necessary. The assumed removal effcienciencies (Table 1) were based on field observations by TNO supplemented with literature data. There are $3 \mathrm{UK}$ plants that are uncontrolled (with $0 \%$ Vanadium removal) and these plants are estimated to account for $50 \%$ of the residual oil consumption in this sector in the UK The average overall removal efficiency for Vanadium for petroleum coke combustion in refineries with ESP is estimated at 50\%., based on a 2005 sample of 5 refineries from a total number of 55 in the area under consideration. Emission factors for coal-fired power plants with FGD (Netherlands, Germany, Denmark) and without FGD (Belgium, United Kingdom) were taken from Meij and Te Winkel (2005). High emission can also occur during the various processes of production of Vanadium but these activities do not occur in the studied area.

\section{Results and Discussion}

Total Vanadium emission in North Western Europe amounts to approximately 1.5 ktonne in 2005 (Table 1). The combustion of residual oil makes the largest contribution ( $\sim 80 \%$ including sea shipping, or $41 \%$ without sea shipping). Petroleum coke contributes $18 \%$ and coal-firing a little over $1 \%$. The largest contribution is made by international shipping (39\%) and petroleum refineries (35\%). Other industries contribute $\sim 19 \%$. Considering that petroleum coke and residual oil are so dominant for $\mathrm{V}$ emission, the accuracy at which the $\mathrm{V}$ content of both fuels is known is critical.

Vanadium is also in increasing amounts used as a catalyst to treat exhaust gas but an indicative calculation (data not shown) showed that the resulting emission is negligible compared to other sources.

Based on our emission inventory about half of the total emission is concentrated at a few locations (Rotterdam, Antwerp, Hamburg). These are densely populated cities, resulting in relatively high exposure of their inhabitants.

Table 1. Assumed Vanadium removal efficiencies per fuel type, for different processes (\%)

\begin{tabular}{lcc}
\hline Process $\quad \backslash$ Fuel & PC $^{\mathbf{a}}$ & HFO $^{\mathbf{a}}$ \\
\hline Electricity generation & $>99$ & $50 / 90 / 95$ \\
Petroleum refineries & $50(0 / 95)$ & 0 \\
Cement/glass production & $>99$ & $>99$ \\
Other industry & $90-99$ & 0 \\
Residential combustion & - & 0 \\
Sea going ships & - & 0 \\
\hline
\end{tabular}

${ }^{\mathrm{a}} \mathrm{PC}=$ Petroleum Coke; HFO $=$ residual oil... 
Table 2. Estimated emission of Vanadium in North Western Europe in 2005, by country ${ }^{\text {a }}$, fuel and sector

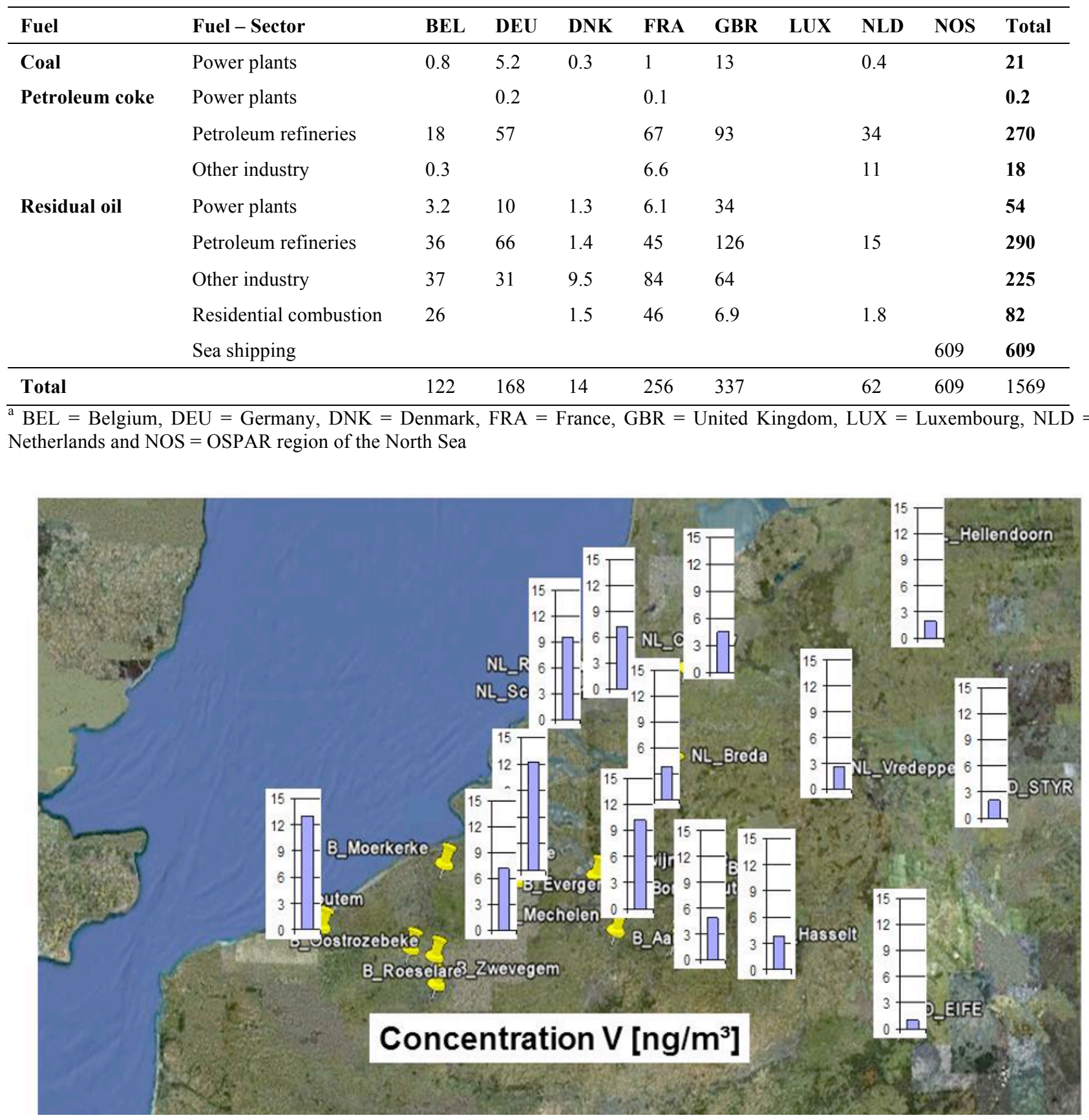

Fig. 2. V concentrations in NW Europe at various distances from the North Sea during 2005 to 2008.

\section{Observational data of Vanadium in air}

To validate the above hypothesis that Major ports are important hot spots of $\mathrm{V}$ emissions we compiled observational data at various locations in the Netherlands, Flanders and Western Germany during the period 2005 to 2008 (Beuck et al., 2011, Vercauteren et al., 2011, Weijers et al., 2011). A clear pattern of decreasing concentration to a factor of 10 is observed moving from the coast line to about $400 \mathrm{~km}$ inland, away from sea going ships and refineries (Fig. 2).
The evolution of annual emissions (Fig. 3) by ships in Rotterdam (top pane), the annual emissions of the refineries situated in the area (middle pane) and the observed annual average Vanadium concentration at Hoek van Holland (close to the harbor mouth) and Bergambacht (about $50 \mathrm{~km}$ inland) (Snijder, 2012). Hoek van Holland shows severely elevated ambient concentrations compared to the observations inland (see also Fig. 2), especially prior to 2009. From 2008 onwards HFO use by ships was not allowed in the Rotterdam port. Simultaneously, V emission at sea was also reduced 
because the $\mathrm{V}$ content of $\mathrm{HFO}$ is related with its $\mathrm{S}$ content, which was lowered from $2.7 \%$ to $1.5 \%$ in 2007 for the North Sea.

Hoek van Holland shows a factor of four total reduction during the last decade, as did the emission from ships at berth. Refinery emission decreased by almost a factor of three, primarily as a result of the phasing out of residual oil as a furnace fuel in favor of natural gas from 2008 onwards. The observed V trend at Hoek van Holland confirms the downward trend in total emissions.
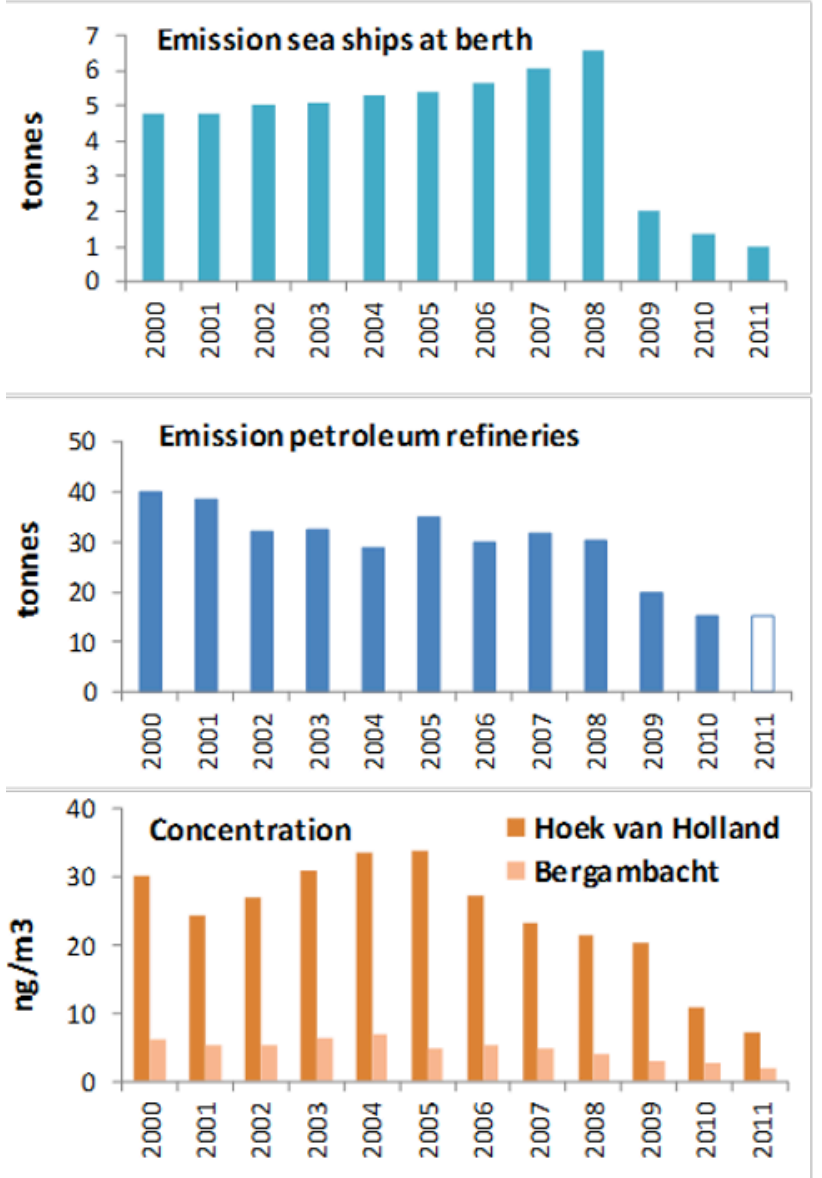

Fig. 3. Time series of Vanadium emission and observed concentrations for the port of Rotterdam

\section{Conclusion}

NW European Vanadium emissions in 2005 amounted to 1569 tons/yr with major ports and nearby industrial complexes being hot spots of $\mathrm{V}$ emissions. The inventory can be used as input for for air quality modeling and tracing the source contributions from certain types of fossil fuels (petroleum coke and residual fuel oil). Monitoring of Vanadium over time could be used to follow transitions in energy systems and /or the impact of user cleaner fuels e.g. in shipping and refineries. Furthermore, the co-benefits of environmental measures like reduction of the $\mathrm{S}$ content of Fuel oil were shown with both hotspot and background $\mathrm{V}$ concentration being reduced by a factor of four over the last decade.

\section{Acknowledgements}

This study was partly funded by EU FP7 ENERGEO. We thank DCMR (Rotterdam), RIVM (Bilthoven) and VMM (Belgium) for sharing their observational data.

\section{References}

Beuck H, Quass U, Klemm O, Kuhlbusch TAJ. Assessment of sea salt and mineral dust contributions to PM10 in NW Germany using tracer models and positive matrix factorization. Atmospheric Environment 2011; 45(32):5813-5821.

IEA. International Energy Agency, Energy Statistics of OECD Countries - 2011 Edition, Data on CD-ROM, ISBN 978-92-64-089877. 2011.

Meij R, Te Winkel BH. The Emissions of Heavy Metals and POP's from Modern Coal-Fired Power Stations. Proceedings of the TFEIP \& ESPREME Workshop Heavy Metals and POPs, Rovaniemi/Finland, Oct 18/19, 2005.

Moreno T, Querol X, Alastuey A, De la Rosa J, Sánchez de la Campa AM, Minguillón MC, Pandolfi M, González-Castanedo Y, Monfort E, Gibbons W. Variations in vanadium, nickel and lanthanoid element concentrations in urban air. Science of The Total Environment 2010; 408(20):4569-4579.

Snijder A, Results for air quality of the Provincial Integral Monitoring Network Environmental Quality (Provinciaal Integraal Meetnet Milieukwaliteit) by the Environmental Protection Agency of the Rijnmond - Rotterdam Area (DCMR). 2012.

Vercauteren J, Matheeussen C, Wauters E, Roekens E, Van Grieken R, Krata A, Makarovska Y, Maenhaut W, Chi X, Geypens B. Chemkar PM10: An extensive look at the local differences in chemical composition of PM10 in Flanders, Belgium. Atmospheric Environment 2011; 45(1):108-116.

Weijers, EP, Schaap M, Nguyen L, Matthijsen J, Denier van der Gon HAC, Ten Brink, HM and Hoogerbrugge R. Anthropogenic and natural constituents in particulate matter in the Netherlands. Atmos. Chem. Phys. 2011; 11:1-14.

WHO. World Health Organization. Air Quality Guidelines, Chapter 6.12 Vanadium, Second Edition. WHO Regional Office for Europe. 2000. 